UDC 615.1:339.138

DOI: $10.15587 / 2519-4852.2020 .222252$

\title{
METHODS OF ASSESSMENT OF QUALITY OF PARTNERSHIP RELATIONS BETWEEN PHARMACEUTICAL MARKET ENTITIES IN THE MEDICINE PROMOTION SYSTEM ON THE BASIS OF MULTICRITERIAL CHOICE
}

\author{
A. Olkhovska, V. Malyi, M. Nessonova, A. Chehrynets
}

\begin{abstract}
The aim. Development of a conceptual model for the formation of strategic partnerships between the subjects of the pharmaceutical market and the effectiveness of their management; development and testing of methods for assessing the quality of partnerships between pharmaceutical market participants in the system of promotion of medicines based on multi-criteria selection.

Materials and methods. Methods of content analysis, logical analysis, grouping, generalization, marketing research, statistical analysis, graphical method and "classification tree" (CART) method were used to implement the outlined research tasks.

Research results. The conceptual model of formation of strategic partnership relations (PR) and efficiency of their management between subjects of the pharmaceutical market (SPM) in system of advancement of medicines (drugs) in the pharmaceutical market is developed, the implementation of which will facilitate the integration of efforts to provide quality pharmaceutical care to the population of Ukraine. According to the expert survey, the importance of the criteria for evaluating SPM partnerships is determined: the duration of the relationship, the depth of the partnership, the possibility of duplication, the reliability and dynamics of the partnership, the effectiveness of the partnership. A method for assessing the quality of PR between SPM in the system of drug promotion based on multicriteria selection using the method of "decision tree", which was tested in the practice of the studied pharmaceutical company $(P C)$ in promoting the pharmaceutical enzyme complex to restore spine and joint function. PR quality assessment between SPM in the pharmaceutical product promotion system according to the developed algorithm is done by sequential comparison of predictors-criteria with the threshold values of their scores, according to which the descent along certain tree branches is reached until a terminal node corresponding to a certain the value (high, medium or low) of the level of quality of the relationship with the partner in the promotion of goods. The overall accuracy of the constructed algorithm is $80.2 \%$. Combinations of values of evaluation of partnership criteria which provide high, average and low level of quality of PR are defined.

Conclusions. The obtained results allowed to determine the group of the most optimal partners of the studied $P C$, which provide effective promotion of the pharmaceutical product on the basis of a high level of PR quality. The developed methodology for assessing the quality of PR between SPM in the system of pharmaceutical promotion based on multi-criteria selection will be useful for SPM who seek to develop and maintain long-term relationships with partners for consolidated cooperation by optimizing marketing activities. The results obtained are of practical importance and can be useful for SPM in order to form an effective and lasting partnership in the field of drug promotion, which will help improve the quality of pharmaceutical care and the availability of drugs for the population
\end{abstract}

Keywords: partnerships, pharmaceutical market players, promotion, medicines, “decision tree” model

Copyright (C) 2020, A. Olkhovska, V. Malyi, M. Nessonova, A. Chehrynets.

This is an open access article under the CC BY license (http://creativecommons.org/licenses/by/4.0).

\section{Introduction}

In the context of globalization of the pharmaceutical market and increasing demand for its products, it is important to establish PR, as building an effective system of relationships in the long run is a prerequisite for market stability of PC and gaining competitive advantage. However, unequivocal recognition by scientists and pharmacy practitioners of the importance of PR issues between SPM does not provide a complete answer to the most effective ways, mechanisms and technologies to develop mutually beneficial cooperation and dissemination of partnership practices. All this determined the relevance of the chosen direction of the research. The development of the general theory of trust between part- ners and directly the trust of the subjects of final consumption as a component of social responsibility of business has been thoroughly influenced by the scientific works of such authors as [1-3]. Assessment and development of relations between business partners and their interaction and current directions of PR formation were considered in $[4,5]$; directly on the formation of international PR in the modern world economy could be found in work [6]; the question of the level of awareness of PC specialists about the basic principles of relationship marketing is covered in the works [7]; research of the system of state regulation of pharmaceutical legal relations in the field of drug circulation, in particular, normative-legal regulation of import-substituting drug production in 
Ukraine, is revealed in the work [8]; issues of improving the logistics service of industrial PC customers as a basis for the formation and development of PR in the transition of industry to quality management were considered in [9, 10]. Given the significant amount of work on business PR and the phenomenon of trust, etc., we can note the growing interest of scientists, researchers and practitioners in the pharmaceutical sector in the formation of effective mutually beneficial cooperation between SPM.

The aim of the research. Development of a conceptual model for the formation of strategic partnerships (PR) between pharmaceutical market participants (SPM) and the effectiveness of their management; development and testing of methods for assessing the quality of PR between SPM in the system of promotion of medicines (drugs) based on multicriteria selection.

\section{Planning (methodology) of research}

The following research plan has been developed:

- analysis and generalization of theoretical and scientific-practical approaches to building an effective PR system;

- building a conceptual model for the formation of strategic PR between SPM and the effectiveness of their management;

- determining the importance of the criteria for assessing the participation of partners - SPM in the joint process of promotion of drugs in the pharmaceutical market using a questionnaire of experts;

- development of a methodology for assessing the quality of PR between SPM in the system of promotion of pharmaceutical products on the basis of multi-criteria selection and its testing in the practice of domestic pharmaceutical enterprises.

\section{Materials and methods}

Methods of content analysis, logical analysis, grouping, generalization, marketing research, statistical analysis, ABC analysis, graphical method and method of "classification tree" (CART) were used to implement the outlined research tasks. Experimental data were processed on a personal computer using software packages Statistica, Microsoft Office Excel.

Criteria assessment of PR between SPM in the system of promotion of drugs in the pharmaceutical market was conducted by us using a questionnaire survey of 160 experts from domestic PCs (manufacturers, wholesalers, pharmacies) and foreign pharmaceutical companies. The experts were heads of structural subdivisions of manufacturers, heads of pharmacies and authorized persons, whose functional or delegating duty is to communicate with the wholesale network and/or structural subdivisions of manufacturing enterprises. The representativeness of the sample was confirmed by appropriate calculations. The number of experts exceeded the number of constituent PR criteria to be ranked in our study. The agreement of the surveyed experts was high, as the value of the concordance coefficient (W) was 0.78 . To assess the significance of the concordance coefficient, the Chisquared test $\left(\chi_{p}^{2}\right)$ was calculated, which is 1622.4 . The calculated $\chi_{p}^{2}$ was compared with the tabular value for the number of degrees of freedom 13 at a significance level of $\alpha=0.05$. The calculated value of $\chi_{p}^{2}$ exceeds the tabular value for the corresponding degrees of freedom $\chi_{\text {tab }}^{2}=22.36203,\left(\chi_{p}^{2}=1622.4>\chi_{\text {tab }}^{2}=22.36203\right)$.

Thus, with a probability of $95 \%$, it can be argued that the non-random consistency of the conclusions of the interviewed experts was determined, and the results obtained during the questionnaire can be used in further research.

The construction of the algorithm (model) of the "decision tree" to determine the optimal PC partner in the system of drug promotion was carried out using the method of "classification tree" (CART). When constructing the "decision tree" the following parameters were used: missclassification cost is equal for all selected classes; a priori probabilities of assigning objects to classes estimated by training sample, goodness of fit - by Gini measure, branching stop rule - direct stop by FACT method with a maximum number of 100 nodes and a share of unclassified observations of not more than $5 \%$. The accuracy of the developed algorithm (model) was evaluated by crossvalidation.

\section{Results of the research}

According to the innovative vector of development of the domestic healthcare sector, the effective functioning of the pharmaceutical sector is significantly related to the quantitative and qualitative indicators of partnerships. At present, in the conditions of globalization of the pharmaceutical market, scientific and applied researches of methodical bases of formation of effective partnership relations between SPM in the field of promotion of medicines in Ukraine and foreign countries are actual.

We have developed a conceptual model of the formation of strategic PR and the effectiveness of their management between SPM in the system of promotion of drugs in the pharmaceutical market, which is shown in Fig. 1.

The process of formation and effectiveness of strategic PR management in the system of drug promotion in the pharmaceutical market is a logical sequence of ten stages, which involve coordination of relationships and regulation, taking into account the impact of macro- and micromarketing environment of SPM operation and interaction.

At the initial stage, an analytical assessment of the system of drug promotion in the pharmaceutical market is carried out. To this end, it is necessary to determine the legal restrictions on the promotion of drugs in the country; selection of possible and appropriate tools that should be used to achieve the goals of the organization; identification of possible problems related to the promotion of drugs in conditions of economic development and fierce competition in the market; formation of a general concept of partnership between SPM in the system of drug promotion. The main principles of determining strategic partners are their prospects for further cooperation, consolidated strategic focus on achieving goals, adequacy and objectivity of management decisions to promote drugs in the pharmaceutical market. 


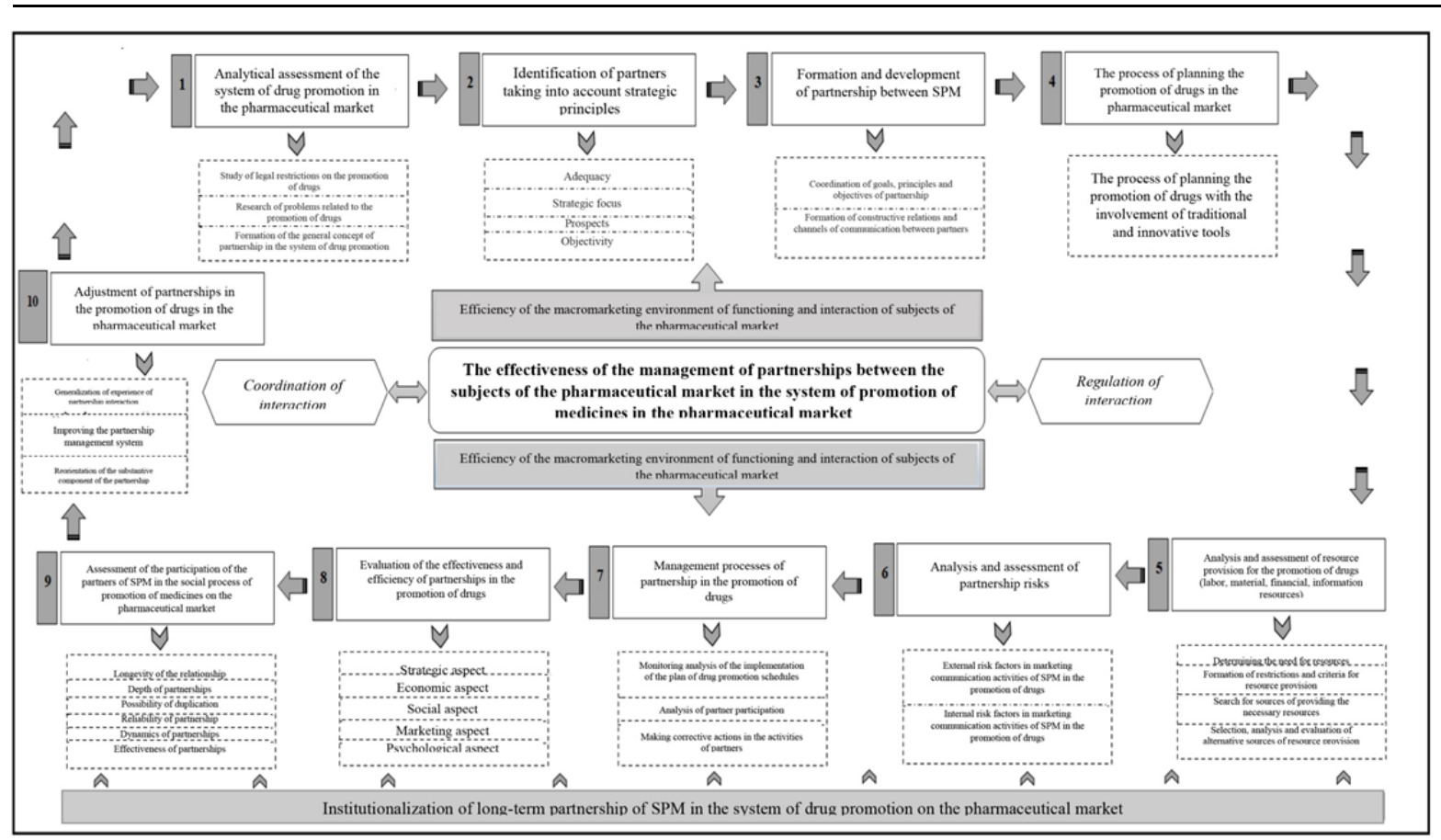

Fig. 1. Conceptual model of formation of strategic partnerships and efficiency of their management between SPM

The formation and development of PR on a strategic basis requires the mandatory coordination of goals, principles and general objectives of partnership and the formation of constructive relationships and channels of communication between partners.

The main measures should be information support of partnership, ensuring the communicative adaptability of SPM. The development of PR involves the use of a strategy to increase the value of drug consumers, aimed at intensifying their purchases and adapting to their response to the incentives of various instruments. In addition, the organization of strategic PR involves the development of joint measures to manage the risks of partnership in the system of promotion of drugs, taking into account external and internal risk factors in the marketing communication activities of SPM. When developing a plan for the promotion of drugs, it is reasonable to approach the choice of the optimal structure of the tools of the MC, taking into account the optimization component of PC costs for their implementation and resource provision. It is important to assess the effectiveness and efficiency of PR in the promotion of drugs, which provides strategic, economic, social, marketing and psychological aspects of the effectiveness of interaction. Strategic effectiveness is determined by the extent to which PR contributes to the achievement of compatible SPM goals; the ability to bridge resource gaps and create competitive advantages; reduction of terms of withdrawal of drugs to the pharmaceutical market; risk reduction; increasing the manageability of the relationship. The economic aspect of PR efficiency is aimed at reducing the cost of joint activities, increasing potential income. The social aspect involves the consolidated efforts of partners to ensure the availability of drugs for all segments of the population. Marketing - involves determining the level of satisfaction with the relationship; strengthening SPM's competitive position and increasing market share; growth of image and reputation of organizations; achieving the benefits of sharing branding and positioning; increasing consumer loyalty, etc. The psychological (behavioural) aspect involves lowering the barrier of consumer distrust of drugs; formation of consumer perception of drugs as a commodity to improve the quality of life, not for treatment.

We consider it appropriate to evaluate the participation of SPM partners in the joint process of promoting drugs in the pharmaceutical market according to the following criteria: duration of PR as a factor of long-term partnership, implementation of which will allow planning costs and time of projects, timeliness and quality of commitments; to avoid risks from storage of production and raw materials, in the course of sale and advancement of medicines; the depth of partnerships as a factor in the level of interaction of partners in different areas of activity. Also within the limits of this criterion are provided: assessment of the presence or absence of the process of joint planning and control of joint activities, creation and functioning of jointly created structures necessary for the best use of the partnership; the possibility of duplication (partner, communication channel, contact), which provides the ability of the company in the shortest possible time to replace one connection with another if the partner for some reason cannot fulfil its partnership obligations. This opportunity is realized due to the availability of contacts and partnership channels; reliability of partnership, which is the result of trust, synchronicity in cooperation; quantitative and qualitative assessment of the partner, which is expressed in such parameters as financial performance, business reputation, ability to execute obligations precisely and on shcedule; dynamics of partnerships as a factor in expanding the scope of PR, development and implementation of new methods of establishing and extending partnerships, penetration with partners into new markets; the effectiveness of PR, which is determined by the ratio of the contract 
amount to total operating income for a particular type of interaction or by comparing the terms of the agreement; directly, the effectiveness of customers can be assessed by the share in total procurement. However, given that these indicators are a trade secret of any business structure, we propose as a criterion for the effectiveness of PR to use the indicator of fulfilment by partners of the following conditions: the possibility of reorientation of activities in accordance with market conditions; the ability of partners to achieve, maintain and strengthen their market competitive advantages in conducting business processes on an independent basis and in comparison on the basis of partnerships.

To determine the importance of the proposed PR criteria, we conducted a questionnaire survey of PCbased experts on a ten-point scale, where 10 points - the highest score of the criterion. Based on the obtained results, the arithmetic mean evaluation of PR SPM criteria was determined. The generalized results are shown in Fig. 2.

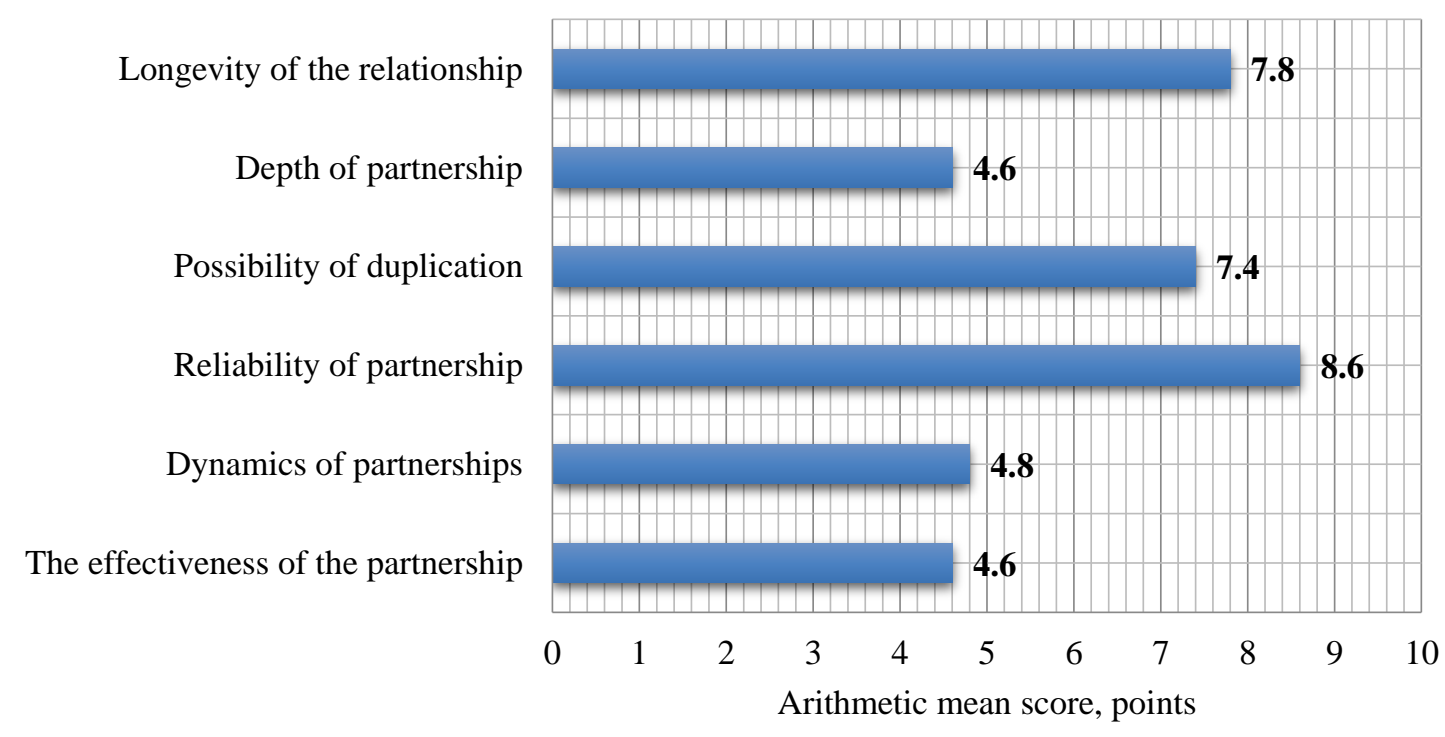

Fig. 2. Assessment of the importance of SPM partnership criteria according to the expert survey

The analysis of the importance of the criteria of partnership between SPM showed that in the first place in the implementation of partnership, according to experts, are such criteria as reliability, durability and the possibility of duplication $(8.6 ; 7.8 ; 7.4$ points, respectively). Against this background, the importance of scoring criteria such as the dynamics of partnerships, their effectiveness and depth $(4.8 ; 4.6 ; 4.6$ points, respectively) are of some concern, as they are indicators, first, of a radical change in approaches to development PR between SPM in the field of drug promotion; secondly - serve as a basis for the development of new business models in the market; third, it is an indicator of market sustainability and the ability of partners to strengthen their market competitive advantages through mutual understanding of the social orientation of the overall mission of the pharmaceutical sector and the importance of PR for its implementation. It should be noted that the results are reduced by the position of the retail sector, whose representatives assessed the components of these criteria as indicating the current irrationality of their interaction with other PR participants and needs some adjustment in the future [11].

The implementation of the proposed conceptual model of PR formation between SPM in the system of drug promotion on a strategic basis will promote the integration of efforts to provide quality pharmaceutical care to the population of Ukraine.

The practical implementation of the formation of strategic PR focuses on the development of methods for assessing the quality of PR between SPM, which will be the basis for selecting optimal partners to ensure the effective promotion of drugs in the pharmaceutical market. Therefore, at the next stage of the study we first developed a method of assessing the quality of PR between SPM in the system of promotion of pharmaceutical products based on multicriteria selection. Approbation of the proposed technique was carried out in the practical activities of the studied PC in the promotion on the pharmaceutical market of the plant enzyme complex to restore the function of the spine and joints. Statistica software (TIBCO Software Inc., USA) was used as a tool to develop the above methodology.

To select the optimal partners of the studied PC, which will be able to ensure effective promotion of the enzyme complex on the basis of quality PR, we used the method of "decision tree" (CART) [12,13]. The input data were the results of evaluation of PR with 101 partners-SPM by PC specialists according to the criteria defined at the previous stage of the study (Table 1). 
Table 1

List of criteria for evaluating partnerships

\begin{tabular}{|c|c|}
\hline $\begin{array}{c}\text { Partnership } \\
\text { criteria }\end{array}$ & Components of partnership criteria \\
\hline \multirow[t]{2}{*}{$\begin{array}{l}\text { Longevity of } \\
\text { partnership }\end{array}$} & $\begin{array}{c}\text { Timeliness and quality of obligations } \\
\text { execution }\end{array}$ \\
\hline & Risk avoidance \\
\hline \multirow{2}{*}{$\begin{array}{l}\text { Depth of } \\
\text { partnership }\end{array}$} & Joint planning process existence \\
\hline & Control over joint activities existence \\
\hline \multirow{2}{*}{$\begin{array}{l}\text { Possibility of } \\
\text { duplication }\end{array}$} & Availability of contacts \\
\hline & $\begin{array}{l}\text { Approachability of partnership commu- } \\
\text { nication channels }\end{array}$ \\
\hline \multirow{3}{*}{$\begin{array}{l}\text { Reliability of } \\
\text { partnership }\end{array}$} & Assessment of trust in partnerships \\
\hline & The grade of business reputation \\
\hline & $\begin{array}{l}\text { The grade of ability to execute obliga- } \\
\text { tions precisely and on shcedule }\end{array}$ \\
\hline \multirow[t]{2}{*}{$\begin{array}{l}\text { Dynamics of } \\
\text { partnerships }\end{array}$} & $\begin{array}{c}\text { Development and implementation of new } \\
\text { methods of establishing and extending } \\
\text { partnerships }\end{array}$ \\
\hline & $\begin{array}{l}\text { Penetration into new markets with the } \\
\text { help of partners }\end{array}$ \\
\hline \multirow{2}{*}{$\begin{array}{l}\text { The effec- } \\
\text { tiveness of } \\
\text { partnerships }\end{array}$} & $\begin{array}{l}\text { Ability to reorient activities in accord- } \\
\text { ance with market conditions }\end{array}$ \\
\hline & $\begin{array}{l}\text { The ability of partners to strengthen their } \\
\text { market competitive advantages }\end{array}$ \\
\hline
\end{tabular}

Each PR criterion was evaluated by experts on a 10-point scale, where 1 point corresponded to ineffective PR, and 10 points - absolutely effective. Generalized PR indicators for each criterion were calculated as the arithmetic mean of the scores of the individual indicators that make it up. According to the results, the experts of the studied PC rated PR with their partners at an above average level. The longevity of PR was estimated at a statistically significantly higher level than their reliability (Wilcoxon $\mathrm{T}=1293, \mathrm{Z}=3.542793$, $\mathrm{p}=0.000396<0.003333)$ and the possibility of duplication (Wilcoxon $\mathrm{T}=1249.5$, $\mathrm{Z}=4.277350, \mathrm{p}=0.000019<0.003333$ ).

For its part, the possibility of duplication was much lower than the depth of partnerships (Wilcoxon $\mathrm{T}=1109, \mathrm{Z}=3.532566, \mathrm{p}=0.000412<0.003333$ ).

In Fig. 3 shows the algorithm for constructing a "decision tree" for the selection of optimal partners of the studied PC on the basis of multi-criteria selection in the process of promoting the pharmaceutical product. When constructing the algorithm (model) of PR quality assessment, the scores of the target indicator were translated into an ordinal scale, on the basis of which the total sample of PC partners for promotion in the pharmaceutical market of the enzyme complex was divided into three segments:

- segment 1: partners with a low level of PR quality - the average score of the generalized partnership indicator does not exceed 5.5 points. This segment includes 28 PC partner companies;

- segment 2: partners with an average level of PR quality - the average score of the generalized partnership indicator is from 6 to 7.5 points inclusive This segment includes $35 \mathrm{PC}$ partner companies;

- segment 3: partners with a high level of PR quality - the average score of the generalized partnership indicator is 8 points and above. This segment includes 38 PC partner companies.

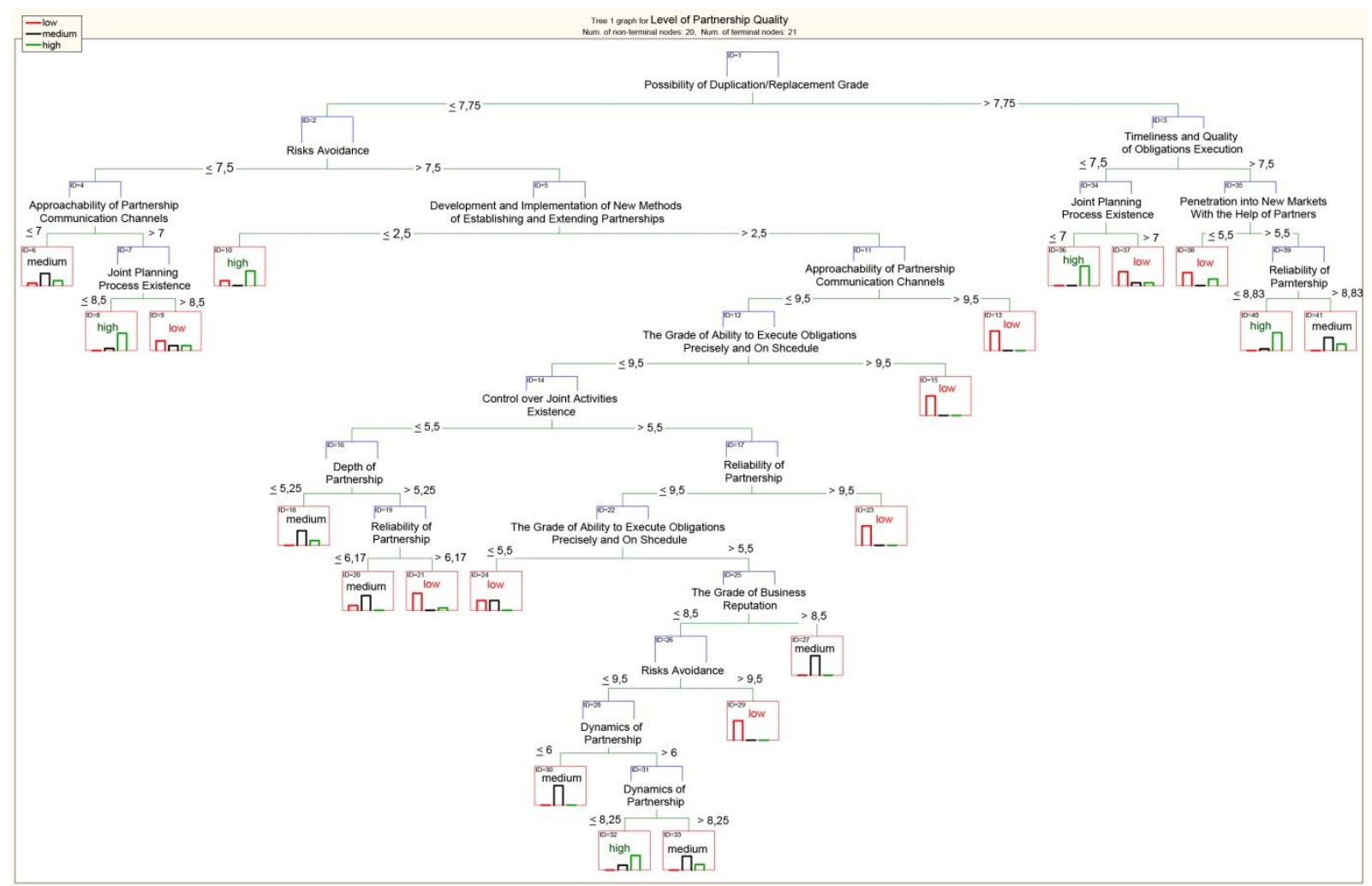

Fig. 3. Algorithm for building a "decision tree" for the selection of optimal partners in the system of promotion of pharmaceutical products based on multicriteria selection 
PR quality assessment between SPMs in the pharmaceutical product promotion system according to the developed algorithm (model) is done by sequential comparison of predictors-criteria with the threshold values of their scores, according to which the descent along certain tree branches until the terminal node is reached, which corresponds to a certain value (high, medium or low) level of quality of the relationship with the partner in the promotion of goods.

The overall accuracy of the constructed algorithm (model) is $80.2 \%$, which is a fairly good indicator of its compliance with the input data. At the same time:

- the accuracy of coverage of the group of partners with a high level of PR quality is $73.7 \%$, and the prognostic accuracy of determining the partners of this class $-87.5 \%$;

- the accuracy of coverage of a group of partners with an average level of PR quality is $80.0 \%$, and the prognostic accuracy of determining this class of partners $-77.8 \%$;

- the accuracy of coverage of the group with a low level of PR $89.3 \%$, and the prognostic accuracy of determining this class of partners $-75.8 \%$.

It should be noted that the constructed algorithm (model) of the "decision tree" shows that the input data have almost no directly proportional dependences such as "if all predictor criteria have high/low scores, then the level of PR quality is likely to be high/low". For the most part, these dependencies are more complex, and a high level of PR quality may be due to high scores on one of the criteria of partnership, provided not high enough scores on a number of other criteria [14].

\section{Discussion of the results}

From the given algorithm (model) it is possible to draw a conclusion that the high level of quality of PR at advancement of the investigated pharmaceutical goods is provided by such combinations of values of estimations of criteria of partnership:

- the assessment of the possibility of duplication exceeds 7.75 points, timeliness and quality of fulfilment of liabilities is estimated at more than 7.5 points, penetration into new markets with the help of partners - more than 5.5 points, but the overall reliability of partnership may be less than 8.33 points;

- the assessment of the possibility of duplication exceeds 7.75 points, but the assessment of the timeliness and quality of fulfilment of liabilities may not exceed 7.5 points, and the joint planning process - 7 points;

- the assessment of the possibility of duplication may not exceed 7.75 points, risk avoidance -7.5 points, the joint planning process -8.5 points, but the assessment of the availability of partnership channels should be more than 7 points;

- the assessment of the development and implementation of new ways of establishing and developing partnerships may not exceed 2.5 points, the possibility of duplication - 7.75 points, but the assessment of risk avoidance provided by the relationship with the partner should be more than 7.5 points;

- the assessments of the availability of partnership channels and the reliability of partnerships may not reach the maximum possible value of 10 points, the grade of business reputation of the partner may not exceed 8.5 points, and the possibility of duplication 7.75 points, but the assessment of development and implementation new ways of establishing and developing partnerships should be at least 3 points, and the assessment of control of joint activities - at least 6 points, in addition, the value of the assessment for the criterion of risk avoidance should be in the range from 7.5 to 9.5 points, for the ability to accurately and timely fulfil the commitments - in the range from 5.5 to 9.5 points and for the dynamics of partnerships - from 6 to 8.25 points.

The average level of PR quality in the promotion of pharmaceutical products is provided by the following combinations of values of the evaluation criteria of the partnership:

- the assessment of the possibility of duplication exceeds 7.75 points, timeliness and quality of obligations execution is estimated at more than 7.5 points, the overall reliability of partnership - more than 8.33 points, penetration through partners into new markets - more than 5.5 points ;

- the assessment of the possibility of duplication does not exceed 7.75 points, availability of partnership channels - 7 points, risk avoidance 7.5 points.

The other four sets of criteria that determine the average level of PR quality have the same common prerequisites, which include requirements for evaluating the development and implementation of new ways of establishing and developing partnerships at more than 2.5 points, duplication - no more than 7.75 points and Approachability of partnership communication channels - 9 points or less. When fulfilling these requirements, the average level of PR quality is achieved by a combination of the following values of the evaluation criteria:

- the assessment of risk avoidance should be greater than 7.5 points, the depth of partnerships - more than 5.25 points, but the assessment of the ability to accurately and timely fulfil liabilities may be 9 points or less, the assessment of joint activities - no exceed 5.5 points, and the reliability of the partnership -6.2 points;

- the assessment of risk avoidance should be higher than 7.5 points, the ability to accurately and timely fulfil the liabilities - no more than 9.5 points, the depth of partnerships - no more than 5.25 points, and the control of joint activities - no more than 5.5 points;

- the grade of business reputation of the SPM partner must be higher than 8.5 points, control of joint activities - more than 5.5 points, risk avoidance - more than 7.5 points, assessment of the reliability of the partnership may be high, but not exceed 9.5 points, but the assessment of the ability to accurately and timely fulfil the liabilities must be in the range from 5.5 to 9.5 points; 
- the grade of business reputation of the SPM partner may not exceed 8.5 points, but under these conditions, to classify the partnership to the average level of PR quality, the assessment of joint control should exceed 5.5 points, the assessment of the reliability of the partnership should not exceed 9.5 points, the assessment of the ability to accurately and timely fulfil the commitments must be in the range from 5.5 to 9.5 points, the assessment of risk avoidance - in the range from 7.5 to 9.5 points, and the assessment of the dynamics of partner ties - in the range of either from 0 to 6 points inclusive, or from 8.25 to 10 points.

All other possible combinations of values of partnership criteria evaluations will indicate a low level of PR quality, which will not ensure effective promotion of the product in the pharmaceutical market.

The obtained results allowed to determine the group of the most optimal partners of the studied PC, which provide effective promotion of the enzyme complex on the basis of a high level of PR quality.

For the final selection of strategic PC partners involved in the promotion of the enzyme complex and ensure its accessibility to the population of the country, we used $A B C$ analysis. The initial data were the annual volume of purchases of the enzyme complex by each partner of the studied PC. The priority partners for cooperation with PC are the enterprises that account for the largest annual volume of purchases of the enzyme complex. According to the results of $\mathrm{ABC}$ analysis, it was found that $79.34 \%$ of the annual procurement of the enzyme complex is provided by 41 PC partners (group A). Group B included 15 partners. Group C consists of 45 partners, which account for the smallest annual volume of procurement of the enzyme complex.

In the following, we compared the previously obtained results of the distribution of partners by PR quality with the results of $\mathrm{ABC}$ analysis and determined that only 18 partners out of 101 are strategically important and the most optimal for further cooperation of the PC. These partner companies have a high level of PR quality in the promotion of pharmaceuticals, due to the ap- propriate combinations of values of the evaluation criteria of the partnership, and fell into group A according to the ABC analysis, which indicates the economic feasibility of further cooperation with them. Potentially optimal partners can also be considered 16 partners from group A, which have an average level of PR quality and 5 partners from group B, which have a high level of PR quality.

Study limitations. The presented algorithm for constructing a "decision tree" for selecting optimal partners in the pharmaceutical promotion system based on multicriteria selection is not sensitive to the number of input variables - with increasing or decreasing the number of partnership criteria, the number of certain tree branches increases or decreases. The logic of the algorithm does not change, which in turn has practical value for all subjects in the pharmaceutical market.

Prospects for further research. It is promising to use the proposed conceptual model of strategic PR formation between SPM and methods of assessing the quality of partnerships in the system of drug promotion based on multicriteria choice when entering international pharmaceutical markets to prevent and/or minimize possible risks and threats from environmental factors.

\section{Conclusions}

Therefore, the developed methodology for assessing the quality of PR between SPM in the system of pharmaceutical promotion based on multi-criteria selection will be useful for SPM who seek to develop and maintain long-term relationships with partners for consolidated cooperation by optimizing marketing activities.

The obtained results are of practical importance and can be useful for SPM in order to form an effective and lasting partnership in the field of drug promotion, which will help improve the quality of pharmaceutical care and the availability of drugs for the population.

\section{Conflict of interest}

The authors declare that they have no conflict of interests.

\section{References}

1. Kuzmin, O. E. (2010). Trust as economic category. Bulletin of NLTU of Ukraine, 20.2, 100-104.

2. Mandibura, V. O. (2010). Restoration of trust of final consumption as a component of social responsibility of business. Theoretical and applied issues of economics, 21, 55-68.

3. Matviishin, E. G., Matviishin, I. L. (2010). Assessment of factors of trust development as a basis for socio-economic growth in the regions of Ukraine. Public administration: theory and practice, 3-4, 230-235.

4. Knyazyk, Y. M. (2010). The relationship of the subjects of marketing partnerships. Bulletin of Lviv Polytechnic National University, 690, 321-326.

5. Us, M. I. (2011). Modern directions of partnership formation. Business Inform, 8, 181-183.

6. Pidgurska, I. (2010). Features of the formation of international partnerships in the modern world economy. Galician Economic Bulletin, 1 (26), 5-11.

7. Piven, E. P., Tkachenko, K. E., Tkachenko, I. V. (2015). Assessment of the level of awareness of specialists of pharmaceutical companies about the basic principles of relationship marketing. Management and marketing in the modern economy, science, education, practice. Kharkiv: NUPh, 218-221.

8. Kotvitska, A. A., Bardakova, L. V. (2016). Research of the system of the state regulation of pharmaceutical legal relationship in the sphere of circulation of medicine. The scientific heritage, 6 (6), 140-143.

9. Posylkina, O. V., Gorbunova, O. Y. (2009). The urgency of establishing a system of partnerships in the logistics chain of a pharmaceutical company. Bulletin of the Donetsk Institute of Road Transport, 1, 242-245.

10. Posylkina, O. V., Gorbunova, O. Y. (2010). Diagnosis of the potential for the development of partnerships in the logistics pharmaceutical chain. Kharkiv: NUPh, 27. 
11. Olkhovska, A. B., Malyi, V. V. (2019). Formation of partnership relations between subjects of the pharmaceutical market in promotion of medicines in Ukraine and foreign countries. Social Pharmacy in Health Care, 5 (1), 31-40. doi: http://doi.org/10.24959/sphhcj.19.146

12. Qabbaah, H., Sammour, G., Vanhoof, K. (2015). Decision Tree Analysis To Improve E-Mail Marketing Campaigns. Information Theories and Applications, 26 (1), 3-36.

13. Hendalianpour, A., Razmi, J., Rameshi Sarvestani, A. (2016). Applying decision tree models to SMEs: A statistics-based model for customer relationship management. Management Science Letters, 6, 509-520. doi: http://doi.org/10.5267/j.msl.2016.5.002

14. Olkhovska, A. B. (2019). Theoretical and scientific-applied principles of improving marketing communications in the system of promotion of drugs in Ukraine. Kharkiv, 44.

Received date 09.11.2020

Accepted date 16.12.2020

Published date 30.12.2020

Anzhela Olkhovska, Doctor of Pharmaceutical Sciences, Associate Professor, Professor, Vice-Rector for Scientific and Pedagogical Work, Department of Pharmaceutical Management and Marketing, National University of Pharmacy, Pushkinska str., 53, Kharkiv, Ukraine, 61002

E-mail: a.olkhovskaya@nuph.edu.ua

Volodymyr Malyi, Doctor of Pharmaceutical Sciences, Professor, Head of Department, Department of Pharmaceutical Management and Marketing, National University of Pharmacy, Pushkinska str., 53, Kharkiv, Ukraine, 61002

E-mail: malyi.vladimir@gmail.com

Maryna Nessonova, PhD, Associate Professor, Department of Educational and Information Technologies, National University of Pharmacy, Pushkinska str., 53, Kharkiv, Ukraine, 61002

E-mail: saddymn@gmail.com

Anna Chehrynets, PhD, Assistant, Department of Pharmaceutical Management and Marketing, National University of Pharmacy, Pushkinska str., 53, Kharkiv, Ukraine, 61002

E-mail: krutskih_ann@ukr.net 